\title{
Holoprinter: study and development of a direct write synthetic full parallax holographic system
}

\section{Holoimpresora: desarrollo e implementación de un sistema de escritura directa para el registro de hologramas sintéticos de paralaje completo}

\author{
Alejandro Madrid-Sánchez ${ }^{1,}{ }^{*}$, Daniel Velásquez-Prieto ${ }^{1}$ \\ 1. Departamento de Ciencias Física, Universidad EAFIT. Medellín, Colombia
}

(*)E-mail: amadrid@eafit.edu.co

Received: 16/04/2018 Accepted: 12/09/2018

DOI: 10.7149/OPA.51.4.50311

\begin{abstract}
:
Holoprinters based on holographic stereograms (HS) have been developed to synthesize holograms by using $2 \mathrm{D}$ images with perspective information of 3D objects. The objects can be real or computer generated. HS has been applied to different fields such as engineering, medicine and military because the high visual impact of the tridimensional and multi-view images it presents. To implement a Holoprinter requires development of three components: i) 2D images generation, ii) optical system design for HS recording and iii) mechanical and control implementation. Therefore, we design and develop each of the components, which integrated compose a holoprinter to synthesize full parallax HS. This paper studies basis for production of this kind of holograms and describes the computational and opto-mechanical design and implementation that we have made. Experimental HS were obtained to validate the system.
\end{abstract}

Key words: Holoprinter, 3D images, holograms, Holography, Holographic display, autostereoscopic, holographic stereogram, synthetic hologram

\section{RESUMEN:}

Las holoimpresoras para el registro de estereogramas holográficos (EHs) se han basado en la síntesis de hologramas usando un conjunto de imágenes 2D con información de objetos 3D que pueden ser reales o generados en computador. Los EHs han sido aplicados en campos como la ingeniería, la medicina y el sector militar gracias al alto impacto visual que presentan sus imágenes tridimensionales con múltiples perspectivas. Implementar una holoimpresora requiere de tres componentes: i) la generación de las imágenes 2D, ii) el diseño de un sistema óptico para el registro de los EHs y iii) la implementación mecánica y de control. Por lo tanto, diseñamos e implementamos cada una de las componentes que conforman una holoimpresora para la síntesis de estereogramas holográficos de paralaje completo. En este trabajo se abordan los fundamentos para la producción de este tipo de hologramas y se describe el diseño e implementación computacional y opto-mecánica que hemos desarrollado. Los EHs obtenidos son presentados como validación del sistema.

Palabras clave: Holoimpresora, Estereograma holográfico, holograma sintético, imágenes 3D, hologramas, holografía, autoestereoscópico.

\section{REFERENCES AND LINKS / REFERENCIAS Y ENLACES}

[1] G. Saxby, Practical Holography, London, Third Edit, IOP Publishing Ltd (2004).

[2] S. Benton and M. Bove, Holographic Imaging, John Wiley \& Sons Inc. (2008). 
[3] A. Madrid-Sánchez, L.M. Giraldo, D. Velásquez-Prieto, "Monocolor and color holography of preHispanic Colombian goldwork: a way of Colombian heritage appropriation", Proceedings of SPIE, 10558, 1055803 (2018).

[4] H. I. Bjelkhagen, "Ultra-realistic 3-D imaging based on colour holography," J. Phys. Conf. Ser., 415, 12023, (2013).

[5] H. Kang, E. Stoykova, N. Berberova, J. Park, D. Nazarova, J. Sup Park, Y. Kim, S. Hong, B. Ivanov, N. Malinowski, "Three-dimensional imaging of cultural heritage artifacts with holographic printers", Proc. SPIE 10226, 19th International Conference and School on Quantum Electronics: Laser Physics and Applications, 102261I (2017).

[6] A. Lembessis, "Hellenic Insitute of Holography", http://www.hih.org.gr/en.html

[7] H. Bjelkhagen and D. Brotherton-Ratcliffe, Ultra-realistic imaging, CRC Press (2013).

[8] J. Svoboda, M. Skeren, and P. Fiala, "Synthetic Image Holograms", Advanced Holography, IntechOpen (2011). Disponible en: https://www.intechopen.com/books/advanced-holography-metrology-andimaging/synthetic-image-holograms

[9] J. Su, X. Yan, Y. Huang, X. Jiang, Y. Chen, T. Zhang, "Progress in the Synthetic Holographic Stereogram Printing Technique", Appl. Sci., 8, 851 (2018).

[10] M. Yamaguchi, "Light-field and holographic three-dimensional displays [Invited]", J. Opt. Soc. Am. A 33 , 2348-2364 (2016).

[11] M. Yamaguchi, "Full-Parallax Holographic Light-Field 3-D Displays and Interactive 3-D Touch", in Proceedings of the IEEE, 105, 947-959 (2017).

[12] H. Kang, E. Stoykova, J. Park, S. Hong, and Y. Kim, "Holographic Printing of White-Light Viewable Holograms and Stereograms", in Holography - Basic Principles and Contemporary Applications, E. Mihaylova, Ed. IntechOpen (2013).

[13] M. Yamaguchi, "Holographic 3-D printer", SPIE Practical Holography IV, 1212, 84-92 (1990).

[14] M. Yamaguchi, N. Ohyama, and T. Honda, "Holographic three-dimensional printer: new method", Appl. Opt., 31, 217-222 (1992).

[15] M. W. Halle, "Multiple Viewpoint Rendering for Three-Dimensional Displays", Doctoral thesis, Massachusetts Institue of Technology (1997).

[16] Holotech Switzerland, "3D Visualization", http://holotech3d.com/index.html [ultimo ingreso: 14Agosto-2018]

[17] Geola, http://geola.com/ [ultimo ingreso: 14-Agosto-2018].

[18] D. J. Debitetto, "Holographic panoramic stereograms synthesized from white light recordings.," Appl. Opt., 8, 1740-1 (1969).

[19] M.W. Halle, "The Generalized Holographic Stereogram", Master thesis, Massachusetts Institute of Technology, (1991).

[20] F.J. Torcal-Milla, M.V. Collados, M. Quintanilla, J. Tornos, J. Atencia, "Realización de estereogramas holográficos a partir de imágenes sintéticas”, Óptica Pura y Aplicada, 44. 185-196 (2011).

[21] T. Honda, M. Yamaguchi, D.-K. Kang, and S. Kei, "Printing of holographic stereogram using liquid-crystal TV," Proc. SPIE 1051, Practical Holography III (1989).

[22] J. Tapsell, "Direct-Write Digital Holography. Development and research of a hologram printer," University of Sussex (2009).

[23] D. Brotherton-Ratcliffe, F. Robert, A. Rodin, and M. Grichine, “Holographic printer,” US 7324248 B2 (2008).

[24] A. Madrid-Sánchez, D. Velásquez-Prieto, "Design, development, and implementation of a low-cost fullparallax holoprinter", Proceedings of SPIE, 10558, 105580H (2018).

[25] M. A. Klug, M. E. Holzbach, A. J. Ferdman, "Method and apparatus for recording holographic stereograms elements using replacable elements", US 8,068,264 B2 (2011).

[26] C. Newswanger, M. Holzbach, and M. A. Klug, "Pulsed laser systems and methods for producing holographic stereograms," US 6806982 B2 (2004).

[27] M. Holzbach, D. T. Chen, "Rendering Methods for full parallax autostereoscopic displays," US Patent, US10058710 (2002). 
[28] J. Su, Q. Yuan, Y. Huang, X. Jiang, X Yan, "Method of single-step full parallax synthetic holographic stereogram printing based on effective perspective images segmentation and mosaicking", Opt. Express, 25, 23523-23544 (2017).

[29] A. Madrid Sánchez and D. Velásquez Prieto, "Computer graphic method for direct correspondence image acquisition used in full parallax holographic stereograms," in Proceedings of SPIE - The International Society for Optical Engineering, 4, 99700F, (2016).

[30] S. Nakamura, J. Minabe, Y. Ogasawara, "Hologram recording device", US 9,939,782 B2 (2018).

[31] J. Geng, "Three-dimensional display technologies", Adv. Opt. Photonics, vol. 5, no. 4, p. 456 (2013).

[32] D. K. Kang, M. Yamaguchi, T. Honda, and N. Ohyama, "Image processing technique for arbitrary image positioning in holographic stereogram," Opt. Commun., 80, 7-12 (1990.)

[33] J. Park, E. Stoykova, H. Kang, S. Hong, S. Lee, and K. Jung, "Numerical reconstruction of full parallax holographic stereograms," 3D Res., 3, 1-6 (2012).

[34] M. W. Halle and A. B. Kropp, "Fast computer graphics rendering for full parallax spatial displays," Proc. SPIE, pp. 105-112, (1997).

[35] D. Brotherton-Ratcliffe, A. Nikolskij, S. Zacharovas, J. Pilechas, and R. Bakanas, "Image capture system for a digital holographic printer," US 2009/0147072 A1 (2009).

[36] K. Yamamoto, R. Oi, T. Senoh, Y. Ichihashi, and T. Kurita, "Holographic stereogram using camera array in dense arrangement," 7957, 795703-795703-9 (2011).

[37] S. Zacharovas, "Advances in digital holography", IWHM 2008 Int. Work. Hologr. 1-11 (2008)

[38] Wikipedia, "List of 3D Computer graphics software", https://en.wikipedia.org/wiki/List of 3D computer graphics software

[39] Autodesk, "Recap", https://www.autodesk.com/products/recap/overview [ultimo ingreso: 14Agosto-2018]

\section{Introducción}

La holografía es una técnica de exhibición tridimensional (3D) que se basa en la interferencia y difracción de las ondas de luz [1,2]. Por su capacidad para registrar la amplitud y fase del frente de onda de los objetos, con la holografía se obtienen imágenes 3D que son difíciles de diferenciar de su objeto original. Por esto ha sido aplicada en diferentes campos, entre estos, la museografía con el propósito de exhibir artefactos patrimoniales para ayudar a su conservación [3-5] y producir museos itinerantes [6], la publicidad y en sistemas de exhibición realistas [7].

Con el desarrollo de las tecnologías digitales se han propuesto diferentes técnicas para sintetizar hologramas de escenas que pueden ser virtuales o físicas. [8-10]. Comparados con la holografía clásica, los hologramas sintéticos utilizan imágenes 2D para almacenar la información tanto de objetos físicos como de escenas creadas en computador. Por su posibilidad para obtener hologramas de objetos que no pueden registrarse analógicamente y su capacidad para integrar tecnologías computacionales, la holografía sintética ha permitido que la holografía como sistema de exhibición 3D se use ampliamente en un ámbito comercial en sectores como la arquitectura, el sector militar, automotriz, médico y el entretenimiento $[2,5$, $7,9]$.

De acuerdo a la información utilizada y a la manera en que esta es registrada, los hologramas sintéticos pueden clasificarse en dos diferentes tipos: los estereogramas holográficos (EHs) y los hologramas generados por computador (HGCs) $[11,12]$. Los estereogramas holográficos están compuestos por un arreglo 2D de hologramas elementales conocidos como hogels $[13,14]$. Cada uno de estos es el registro holográfico de una imagen 2D capturada por una cámara fotográfica o generada en computador a partir de técnicas de renderizado de imágenes. Cuando el EH es iluminado por una fuente de luz blanca, la información de paralaje es reconstruida por el conjunto de imágenes 2D, generando en el observador una experiencia estereoscópica y de cambios de perspectiva de la escena 3D. De esta forma, el observador percibe una imagen 3D sin el uso de ningún dispositivo ocular y las diferentes perspectivas de la escena son generadas para cada posición del observador [7, 15]. Por otro lado, en el caso de los HGCs son utilizados diversos métodos computacionales basados en el cálculo del patrón de difracción de fuentes de luz puntuales [11]. De esta forma, el frente de onda de la nube de puntos de la escena 3D es calculado sobre el plano del holograma. Cada uno de estos patrones de interferencia es impreso o registrado holográficamente 
en un material fotosensible [10-12]. Cuando el HGC es iluminado correctamente, el frente de onda de la escena 3D es reconstruido. Los EHs comparados con los HGCs no requieren de ningún cálculo complejo de difracción para obtener la información de la escena 3D, por lo que el costo computacional se reduce significativamente y adicionalmente, presenta la ventaja de obtener la información de las escenas 3D de manera directa a partir de cualquier software de computación gráfica 3D [11]. Gracias a su alto impacto visual y su capacidad para reducir la cantidad de información requerida en su registro, esta técnica ha sido ampliamente utilizada por grupos de investigación y empresas en el sector académico y comercial $[7,9,16$, 17].

Diferentes tecnologías han sido propuestas para la composición de un EH. Estas pueden ser clasificadas en dos tipos: impresoras de hologramas sintéticos de dos pasos e impresoras de hologramas sintéticos de escritura directa. Las impresoras de hologramas sintéticos de dos pasos se basan en la técnica de hologramas plano imagen [1, 2]. Un primer holograma es registrado a partir de las diferentes imágenes 2D de la escena y son expuestas en el material fotosensible en forma de rendijas rectangulares. Para generar una experiencia estereoscópica, es necesario registrar un segundo holograma a partir de la información del primer holograma. De esta forma, los observadores pueden percibir un par estereoscópico a partir de las rendijas que fueron expuestas inicialmente. A medida que el observador se desplaza horizontalmente, este puede percibir cambios de perspectiva solo horizontal de la escena [18-20]. Debido a la cantidad de información y de procesos que se requiere, estos sistemas son utilizados para producir estereogramas holográficos de paralaje solo horizontal (EH-PH). Por otro lado, para el registro de EHs con cambios de perspectiva tanto horizontal como vertical, llamados EH de paralaje completo (EH-PC), es necesario exponer elementos cuadrados contiguos en todo el plano de la placa en lugar de rendijas [20].

La impresora de hologramas sintéticos de escritura directa fue propuesta por Yamaguchi et al. $[13,14]$ para generar EH de paralaje completo (EH-PC) sin realizar un doble registro. Sus imágenes 3D estaban libres de distorsiones y podían ser vistas para cualquier posición del observador [13]. Yamaguchi propuso un sistema automático para el registro de EHs, en el que usó un modulador espacial de luz (SLM) para proyectar secuencialmente cada una de las imágenes 2D de la escena [21]. A partir de un sistema óptico de escritura, cada una de las imágenes era registrada como un holograma de volumen, denominado hogel. Y de esta forma, el EH era compuesto por un arreglo de hogels que eran registrados punto a punto sobre el material fotosensible. Yamaguchi llamó a su sistema impresora holográfica 3D, en la literatura este sistema es conocido como holoimpresora [22-24]. Basados en los trabajos de Yamaguchi y de los avances llevados a cabo por el grupo de investigación liderado por Benton [19], Zebra Imaging Inc desarrolló una holoimpresora y diferentes métodos computacionales que permitieron aplicar exitosamente los EHs a la industria militar, médica y en arquitectura [25-27]. Posteriormente, Brotherton-Ratcliffe [23] propuso el uso de láseres pulsados para disminuir significativamente los tiempos de registro. Con nuevos diseños ópticos de escritura y la integración de láseres RGB obtuvo EHs de gran formato a color y con un campo visual grande [17, 22, 23]. Los resultados logrados por estos grupos de investigación y empresas han probado que los EHs elaborados por las holoimpresoras de escritura directa presentan posibilidades de imágenes 3D nunca antes logrado. En la actualidad, diferentes métodos computacionales [9, 24, 28, 29], configuraciones ópticas $[29,30]$, materiales y aplicaciones $[7,9]$ son objetos de estudio y desarrollo para la producción de EHs de paralaje completo.

Para desarrollar e implementar una holoimpresora de escritura directa es necesario: i) la generación de las imágenes 2D con la información de la escena 3D y ii) un sistema opto-mecánico que de forma autónoma registre el conjunto de hogels que compone el EH. Las imágenes 2D que son registradas en los hogels presentan la información de intensidad y dirección de los diferentes rayos de luz reflejados por la escena y que están asociados a las posiciones en el espacio del observador [31]. Usualmente, estas imágenes, llamadas imágenes hogel, son generadas a partir de un conjunto de imágenes de las diferentes perspectivas de la escena que son capturadas por cámaras fotográficas o generadas por computador usando modelos de cámaras virtuales [7]. Para producir la experiencia estereoscópica y de cambios de paralaje en un observador, las imágenes de perspectivas deben ser transformadas pixel a pixel para generar el conjunto de imágenes hogels, lo que requiere de tiempo y recursos computacionales significativos [7, 19, 32, 33]. Para el sistema opto-mecánico debe ser diseñado una configuración óptica con la capacidad de registrar un holograma de volumen de la imagen presentada en el SLM y de forma simultánea, definir sobre el área de exposición el tamaño y geometría del hogel. De esta forma, la elaboración de una holoimpresora presenta grandes requerimientos técnicos y tecnológicos en los campos de la computación, el diseño óptico y en implementaciones mecánicas y de control. Estos sistemas deben ser investigados y desarrollados de forma 
integral para producir EHs de paralaje completo con campos visuales (FOV) grandes, imágenes 3D libres de distorsiones y con el mínimo tiempo de impresión [22-27].

Este trabajo reporta el desarrollo de una holoimpresora y describe la implementación de los métodos computacionales y de los sistemas opto-mecánicos para el registro de EHs de paralaje completo de escenas reales o generadas en computador. Para la generación de las imágenes hogel se propone una configuración usando cámaras virtuales. Las imágenes hogel se obtienen de manera directa sin requerir de los algoritmos utilizados en la literatura para la transformación pixel a pixel de las imágenes 2D [29, 34]. Esta configuración se puede llevar a cabo usando softwares de computación gráfica 3D. Con el sistema opto-mecánico diseñado pueden ser registrados EHs de diferentes formatos y tamaños de hogel. Las imágenes 3D obtenidas tienen un amplio campo visual dentro del cual se presentan múltiples cambios de perspectivas y se percibe fácilmente la profundidad de la escena.

El artículo está estructurado de la siguiente manera: en la sección 2, se discuten los principios básicos de la técnica de estereoscopía holográfica. En la sección 3 son descritas en detalle las diferentes implementaciones realizadas en la construcción de la holoimpresora, desde la etapa computacional hasta la opto-mecánica y de control. Y finalmente en la sección 4, las reconstrucciones de los EHs de paralaje completo obtenidos con el sistema propuesto son presentados y discutidos.

\section{Fundamentos de estereoscopía holográfica}

\section{2.a. Generación de las imágenes hogel}

Los estereogramas holográficos (EHs) combinan el principio de la holografía y de la visión estereoscópica. A partir de la holografía es almacenado un conjunto de imágenes 2D con la información de paralaje de las escenas. Cuando cada hogel es reconstruido, la información de paralaje se presenta de manera direccional, y de esta forma, cada ojo del observador puede percibir una imagen 2D de manera independiente para producir una experiencia estereoscópica y de cambios de perspectivas de la escena. Los primero EHs fueron obtenidos por DeBitetto y solo podían generar cambios de perspectivas horizontales de una escena [18]. Para lograrlo, DeBitetto propuso el método de registro de dos pasos y utilizó un conjunto de fotografías con información de las diferentes perspectivas de una escena para producir la experiencia estereoscópica. Cada uno de los fotogramas fueron proyectados secuencialmente sobre una pantalla traslúcida y registrados en un primer holograma de transmisión en forma de rendijas rectangulares. Debido a la manera en que se obtuvieron y registraron el conjunto de imágenes 2D, las imágenes 3D producidas por sus EH-PH solo podían ser vistos en un plano específico de observación [7]. Con el objetivo de eliminar la restricción del plano de observación de los EHs, Halle y Benton [19] propusieron el primer método computacional de remuestreo de imágenes. En su trabajo propusieron diferentes configuraciones de cámaras para obtener el conjunto de imágenes perspectivas de la escena y tomando diferentes fragmentos de estas, compusieron un nuevo conjunto de imágenes 2D que registraron en cada rendija del EH [19]. Basados en los trabajos de DeBitteto y Halle, se han propuesto diferentes configuraciones de cámaras para la captura de las imágenes perspectivas de una escena [7,33]. En el caso de los EH-PH, las imágenes perspectivas son capturadas por un conjunto de cámaras organizadas horizontalmente o por una sola cámara que se desplaza a lo largo de un riel horizontal [35]. Para los EH-PC se utiliza un arreglo bidimensional de cámaras para capturar las perspectivas horizontales y verticales de la escena, y que posteriormente son transformadas en el conjunto de imágenes hogel [36]. Con los avances de la computación gráfica 3D, los métodos para la captura de las imágenes perspectivas se han llevado a cabo a partir del uso de cámaras virtuales y las técnicas de renderización de imágenes [7, 29, 33]. Adicionalmente, la computación gráfica ha permitido implementar otros métodos computacionales que no requieren de aplicar algoritmos de remuestreo, por lo que el conjunto de imágenes hogel son obtenidas de manera directa [33, 34].

Las imágenes hogel que son usadas en los EH-PC por escritura directa pueden ser generadas de dos formas posibles: a) calculando la apariencia de las imágenes hogel desde los puntos de vista del observador [7, 9, $15]$ y b) calculando la apariencia desde las aperturas del EH [9, 15, 33, 34].

a) Métodos de puntos de vista

Los métodos basados en los puntos de vista utilizan una cámara que se posiciona en diferentes puntos del espacio del observador para capturar las imágenes perspectivas de la escena. Estos métodos buscan capturar la información de la escena desde los puntos en que será percibida por el observador. 
Posteriormente, se hace necesario utilizar algoritmos de remuestreo para transformar pixel a pixel las imágenes perspectivas en información de paralaje y así, permitir que los observadores puedan visualizar desde diferentes distancias del EH-PC, dentro de la zona de visualización. Consideremos un plano compuesto por un arreglo de $K x L(k=1,2,3, \ldots K ; l=1,2,3, \ldots L)$ cámaras que capturan las imágenes perspectiva de la escena, cada una de estas de resolución $N x M(i=1,2,3, \ldots N ; j=1,2,3, \ldots M)$ pixeles y que son definidas como $\boldsymbol{C}_{\boldsymbol{k}, \boldsymbol{l}}(\boldsymbol{i}, \boldsymbol{j})$. En los métodos basados en los puntos de vista, como se ilustra en la Fig. 1 , el plano imagen y el plano sobre el cual se desplaza la cámara ("plano cámara") corresponden respectivamente al plano del EH y a su zona de visualización. De esta forma, como se ilustra en la Fig. 2, todos los pixeles de una misma posición del conjunto de imágenes perspectivas $\boldsymbol{C}_{\boldsymbol{k}, \boldsymbol{l}}(\boldsymbol{i}, \boldsymbol{j})$ son extraídos para generar una nueva imagen $\boldsymbol{h}_{\boldsymbol{i}, j}(\boldsymbol{k}, \boldsymbol{l})$ correspondiente a la imagen hogel. De esta forma, $N x M$ imágenes hogel son generadas con una resolución $K x L$ pixeles. La transformación pixel a pixel realizada por los métodos de remuestreo se describe por la ecuación (1) [9, 33].

$$
h_{i, j}(k, l)=C_{k, l}(i, j)
$$

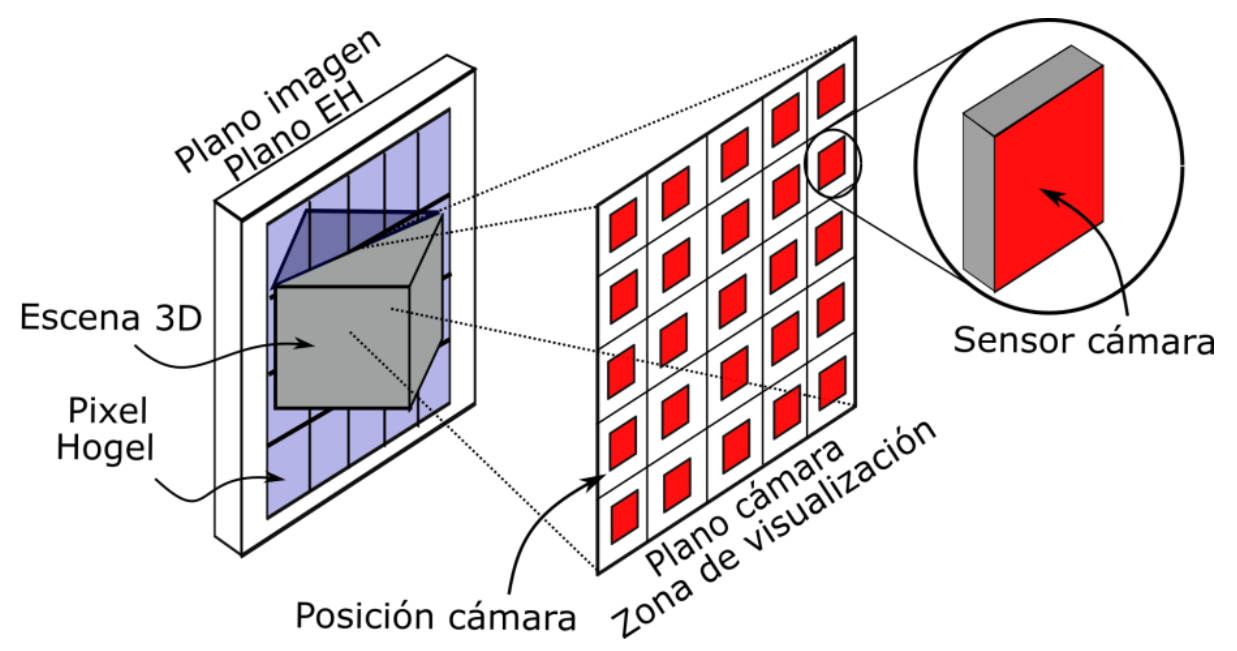

Fig. 1. Generación de imágenes hogel a partir de las imágenes de perspectivas capturadas en los puntos de vista del observador.

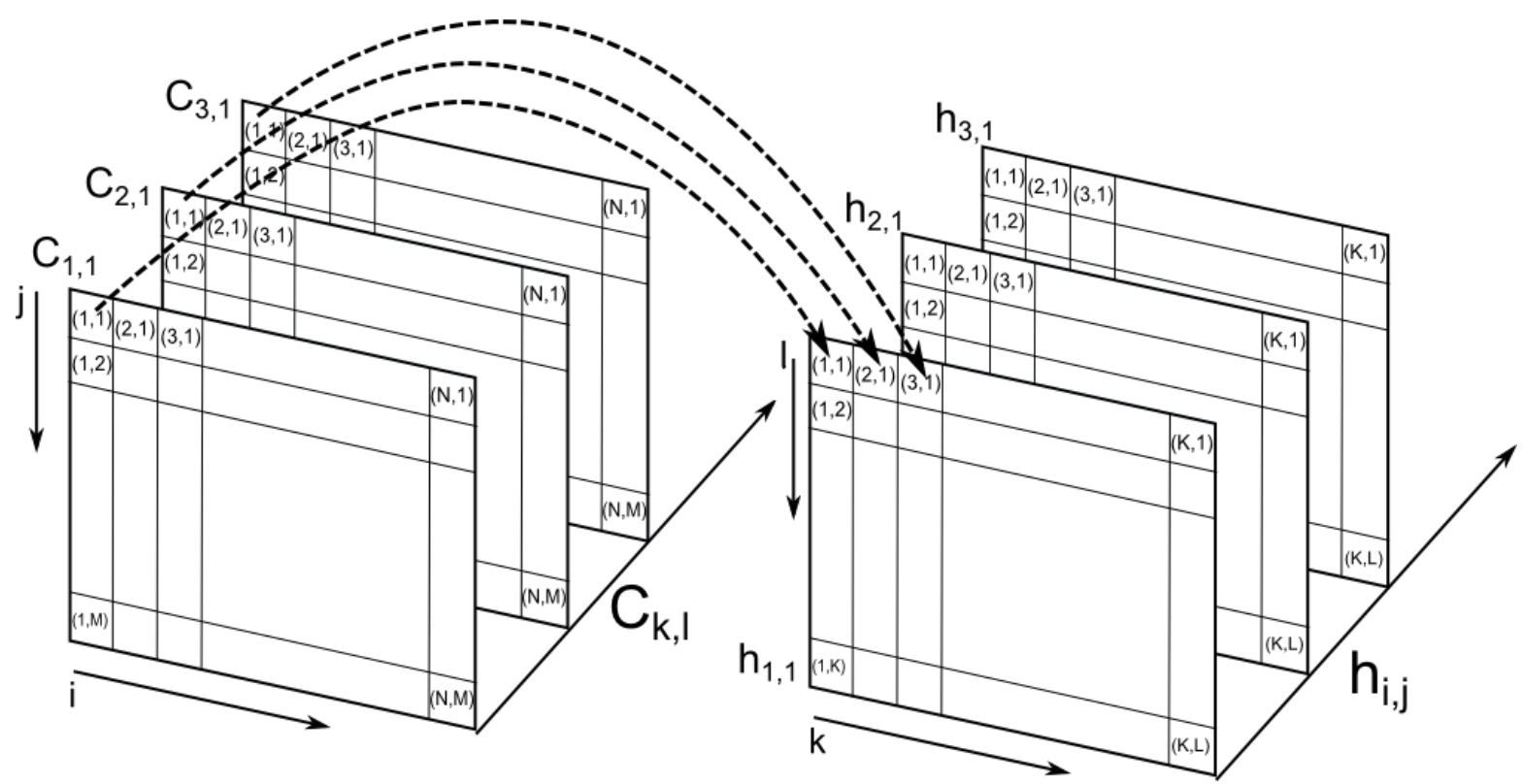

Fig. 2. Algoritmo de remuestreo de pixeles aplicado sobre las imágenes perspectivas (izquierda) para la obtención de las imágenes hogel (derecha). Todos los pixeles de una misma posición del conjunto de imágenes perspectivas $\boldsymbol{C}_{\boldsymbol{k}, \boldsymbol{l}}(\boldsymbol{i}, \boldsymbol{j})$ son extraídos para generar una nueva imagen $\boldsymbol{h}_{i, j}(\boldsymbol{k}, \boldsymbol{l})$ correspondiente a la imagen hogel. 


\section{b) Métodos de apertura}

Por otro lado, los métodos de apertura solo pueden ser aplicados utilizando una cámara virtual para obtener de manera directa la información de paralaje de las escenas. A diferencia de los métodos basados en los puntos de vista, los métodos que parten de las aperturas de los EH no requieren aplicar ninguna transformación de remuestreo para obtener las imágenes hogel. En este caso, cada uno de los hogels que son registrados en el material fotosensible determinan la cantidad de rayos de luz que son emitidos y el campo visual dentro del cual el observador puede percibir información de la escena. De esta forma, los hogels funcionan como una pequeña apertura del EH-PC. Consideremos ahora un EH-PC compuesto por $N \times M$ hogels, en cada uno de estos se registrará una imagen hogel $\boldsymbol{h}_{\boldsymbol{i}, j}(\boldsymbol{k}, \boldsymbol{l})$ de resolución $K \times L$ pixeles. En el caso de los métodos basados en las aperturas, el plano del EH y el plano de proyección de cada hogel corresponden respectivamente al plano cámara y al plano imagen de la cámara. De esta forma y como se ilustra en la Fig. 3, por cada hogel debe ser capturada una única imagen $C$ de resolución $K x L$ pixeles. Todos los pixeles de una imagen $\boldsymbol{C}_{\boldsymbol{i}, \boldsymbol{j}}(\boldsymbol{k}, \boldsymbol{l})$ contienen la información de la imagen hogel $\boldsymbol{h}_{\boldsymbol{i}, \boldsymbol{j}}(\boldsymbol{k}, \boldsymbol{l})$. La generación de las imágenes hogel usando los métodos de apertura es descrita de manera general por la ecuación (2) [33, 34].

$$
h_{i, j}(k, l)=C_{i, j}(k, l)
$$

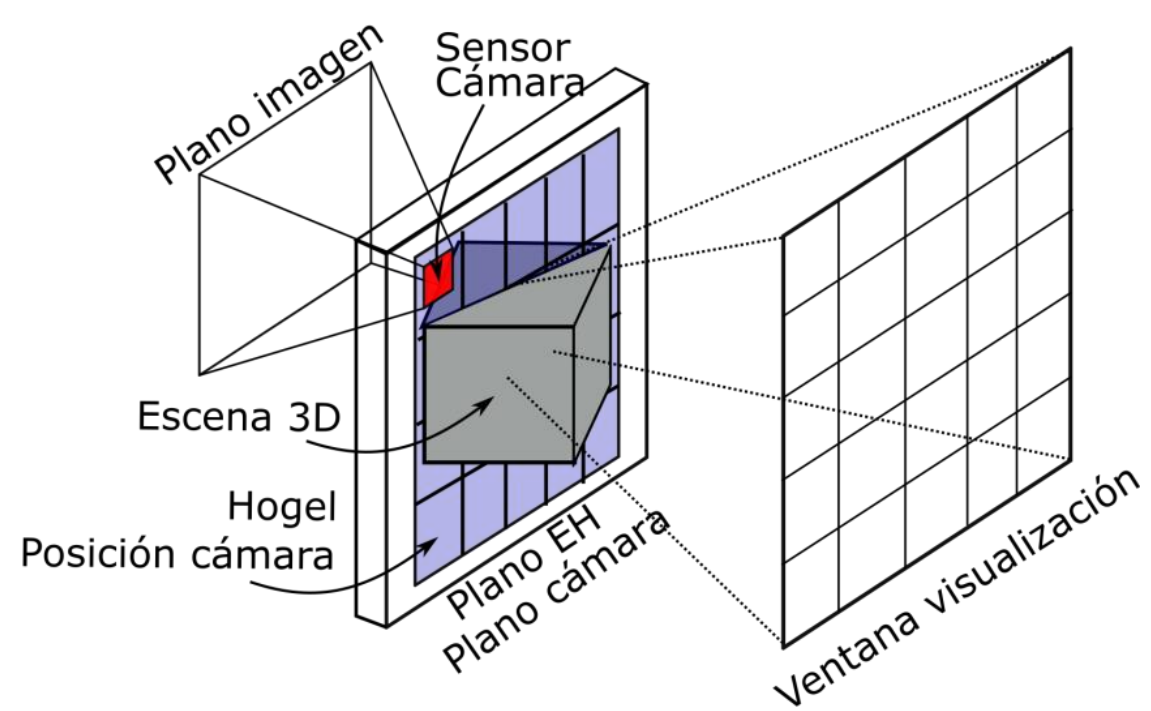

Fig 3. Generación de imágenes hogel a partir de cámaras virtuales posicionadas en cada apertura del EH-PC.

\section{2.b. Registro}

Las holoimpresoras de EH-PC por escritura directa son sistemas opto-mecánicos que permiten el registro de un arreglo de hogels de manera secuencial, rápida y estable. Su configuración óptica se basa en una configuración de hologramas de reflexión, en el que un haz de luz coherente es dividido en dos caminos ópticos, que luego se hacen interferir sobre el material fotosensible [1, 2]. A diferencia de la holografía clásica, el haz objeto de una holoimpresora utiliza un modulador espacial de luz (SLM) para proyectar una imagen 2D, la cual es utilizada como señal objeto del holograma, y utiliza un sistema óptico de escritura compuesto por lentes esférica para generar hogels con campo de visión grande y con información de paralaje tanto horizontal como vertical $[13,14]$. En la Fig. 4 se muestra un esquema de la configuración óptica de registro de una holoimpresora. Este sistema consiste de una fuente de luz coherente, que es dividida en dos haces, un haz objeto y un haz referencia. El haz objeto se propaga a través de un modulador espacial de luz (SLM) en el que se presentan de forma secuencial las imágenes hogel. Estas contienen la información de paralaje de la escena y son generadas a partir de los métodos discutidos en la sección 2.a. Cada una de las imágenes hogel es expuesta sobre el material fotosensible usando un sistema óptico de escritura de apertura numérica grande [7, 22, 23]. De esta forma, el material fotosensible es posicionado cerca del punto focal del sistema óptico de escritura y la información de la imagen hogel es expuesta dentro de una pequeña apertura que compone el hogel.

El haz referencia es configurado para exponer el material fotosensible desde el lado opuesto del haz objeto. De esta forma, se expone sobre el material fotosensible la misma área que la generada por el haz objeto. Con 
la interferencia entre el haz objeto y el haz referencia se producen pequeños hologramas de reflexión de la imagen presentada en el SLM. Para registrar de manera secuencial y automática cada una de las imágenes hogel, el SLM y todas las componentes opto-mecánicas deben ser controlados por computador. Los sistemas de control permiten ajustar el paso y la exposición de cada uno de los hogels de manera precisa y rápida. Finalmente, el EH-PC puede ser reconstruido a partir de una fuente de luz blanca que incida bajo las mismas condiciones geométricas del haz referencia.

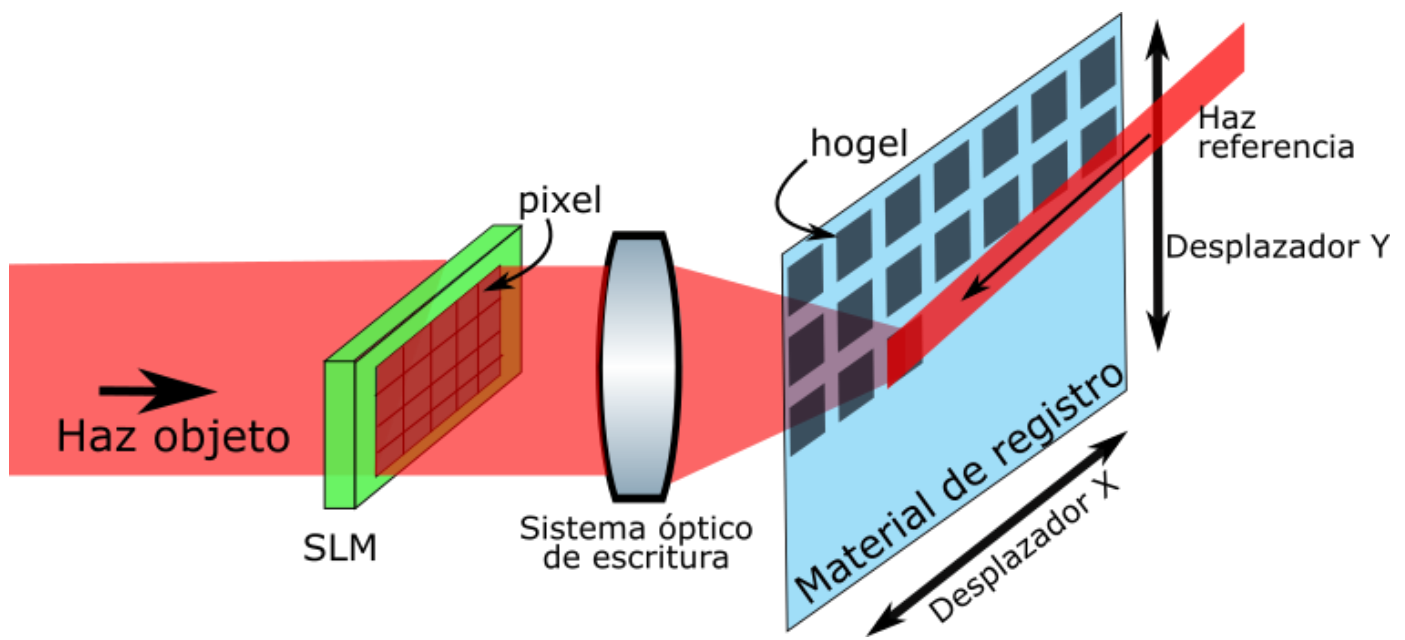

Fig. 4. Esquema del sistema óptico de registro de un EH-PC bajo una configuración óptica de escritura directa. Cada imagen con la información de la escena es proyectada en un SLM y enfocada por un sistema óptico de apertura numérica grande sobre un material fotosensible.

\section{2.c. Reconstrucción de la imagen en un EH-PC}

Un EH pueden ser descrito usando un modelo estereoscópico [7, 15]. Considerando el esquema de la Fig. 5, cada hogel ubicado sobre la superficie del EH-PC actúa como un emisor direccional de la información presentada en el SLM. Estos emiten un conjunto de rayos con direcciones e intensidades diferentes sobre la zona de visualización. En esta zona, cada ojo del observador intercepta los rayos de luz emitidos por los hogels y de esta forma, el observador percibe por cada ojo una única imagen 2D. Los valores de intensidad y dirección de cada rayo de luz son calculados para que correspondan con los rayos de luz reflejados por las escenas $[7,15,31]$. El sistema óptico de escritura determina la distribución angular $(\theta)$ de rayos de luz tanto horizontal como vertical. Y sus valores de intensidades son modulados por la imagen presentada en el SLM. De esta forma, el sistema óptico de escritura determina el campo visual (FOV) en el que el observador puede percibir las diferentes perspectivas de la escena. El campo visual de observación del EH-PC para una holoimpresora de escritura directa queda definido por la ecuación (3), donde $\theta$ es el FOV en grados y AN la apertura numérica del sistema óptico de escritura [7].

$$
\theta=2 * \sin ^{-1}(A N)
$$

Debido al sistema óptico de escritura, cada pixel del SLM está asociado a una perspectiva diferente de la escena. De esta forma, la cantidad de cambios de perspectivas que puede presentar un EH-PC está determinado por la resolución del SLM y el FOV del sistema óptico de escritura, ecuación (3). Finalmente, la resolución de la imagen 2D percibida por un observador en la zona de visualización está dada por la cantidad de hogels registrados en el material fotosensible. Estas restricciones pueden resumirse en la ecuación (4).

$$
\begin{aligned}
& \text { Cantidad perspectivas }=K \times L \\
& \text { Resol. Imagen del } E H=N \times M
\end{aligned}
$$

De acuerdo a lo anterior, podemos entender la imagen 3D producida por un EH-PC a partir de un modelo estereoscópico. La percepción de disparidad binocular, de estereopsis y los cambios de paralaje son generados en un observador a partir de las distribuciones de intensidades producidas por los hogels. La resolución de las imágenes hogel $\boldsymbol{h}_{i, j}(\boldsymbol{k}, \boldsymbol{l})$ determinan los diferentes puntos de vista del observador dentro de la zona de visualización. Y la información que presentan busca reproducir lo más realista posible la intensidad y dirección de los rayos de luz de una escena física o generada en computador. 


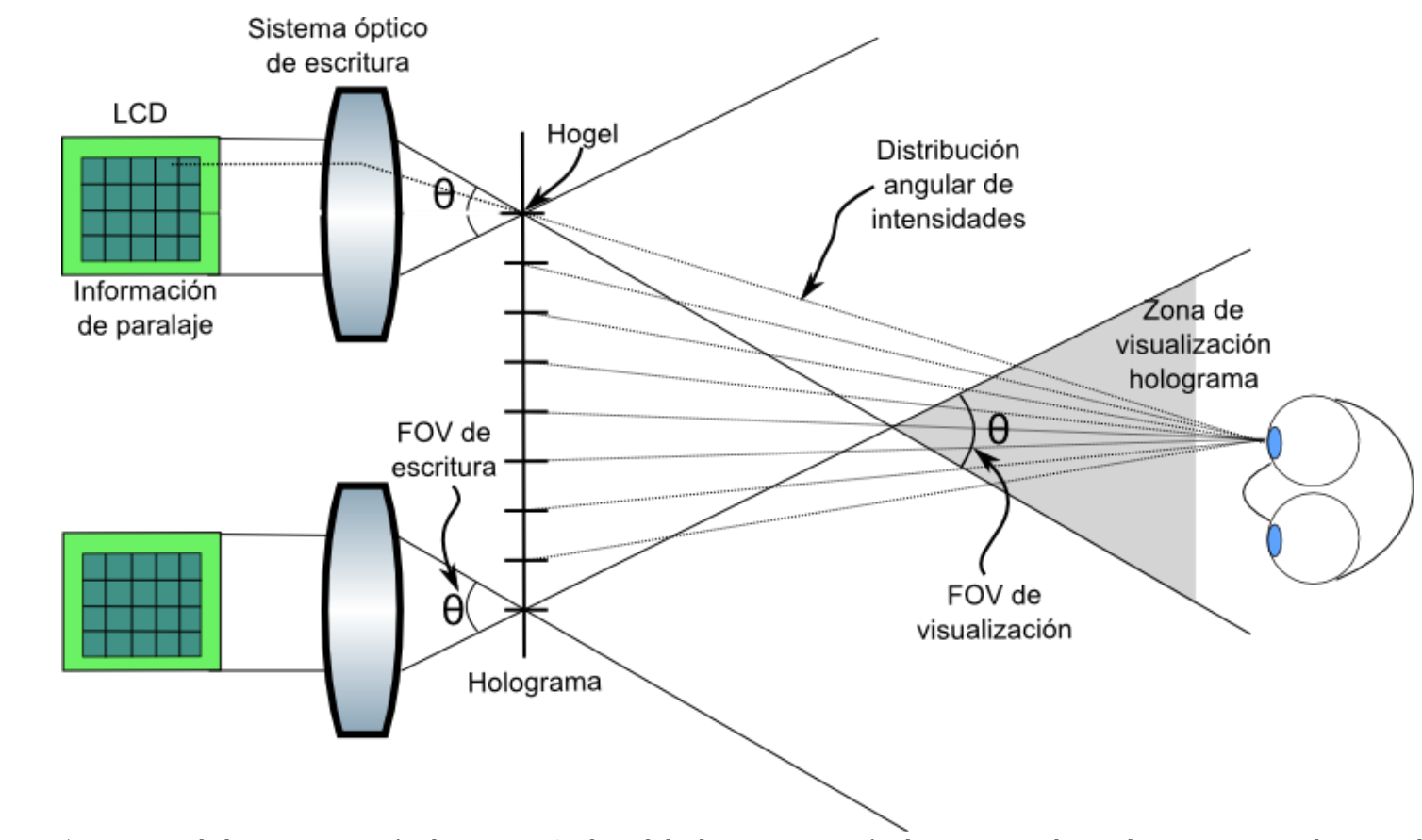

Fig.5. Esquema de la reconstrucción de un EH-PC. El modelo de reconstrucción de un EH puede ser descrito a partir de un modelo estereoscópico. Cada ojo percibe una imagen 2D de manera independiente que es compuesta por los rayos de luz emitidos por cada uno de los hogels.

\section{Implementación de la holoimpresora}

\section{3.a. Implementación computacional}

Todo registro de un EH-PC parte de la información de la escena 3D. Estas pueden ser escenas físicas o escenas que son generadas en computador usando softwares de computación gráfica. Si se desea sintetizar un holograma de una escena física, las imágenes hogel $\boldsymbol{h}_{\boldsymbol{i}, j}(\boldsymbol{k}, \boldsymbol{l})$ pueden generarse a partir de las imágenes perspectivas $\boldsymbol{C}_{\boldsymbol{k}, \boldsymbol{l}}(\boldsymbol{i}, \boldsymbol{j})$ capturadas por una cámara fotográfica. El conjunto de imágenes $\boldsymbol{C}_{\boldsymbol{k}, \boldsymbol{l}}(\boldsymbol{i}, \boldsymbol{j})$ deben ser transformadas posteriormente utilizando el método de remuestreo descrito por la ecuación (1). Con el desarrollo de la computación gráfica 3D y de la visión por computador, diferentes métodos computacionales han sido creados para generar un modelo digital 3D de una escena física a partir de un conjunto de imágenes de perspectivas capturadas por una cámara convencional [7, 37]. La posibilidad de digitalizar las escenas físicas permite utilizar los métodos de generación de imágenes hogel basados en las aperturas del EH, los cuales presentan una calidad superior de imágenes hogel y requieren de un menor costo computacional que los métodos basados en los puntos de vista. En este trabajo, el método computacional de cámara truncada, el cual pertenece a los métodos de apertura, fue desarrollado e implementado para generar las imágenes hogel de escenas físicas y generadas por computador.

Existen diversos softwares gráficos 3D que pueden ser utilizados para la creación y edición de las escenas 3D. Con el uso de estos softwares se busca aplicar las transformaciones geométricas que permita ajustar las dimensiones de la escena a las condiciones de registro del EH-PC, crear las fuentes de iluminación y texturas que brinde las características más realistas posibles, y finalmente construir y utilizar los modelos de cámaras virtuales para la generación de las imágenes hogel [7]. Algunos de los softwares de computación gráfica más usados para el desarrollo de animaciones o la generación de imágenes con efectos especiales son por ejemplo: Autodesk Maya ${ }^{\circledR}$, Autodesk $3 \mathrm{ds}$ Max®, Blender ${ }^{\mathrm{TM}}$, entre otros [38]. Autodesk $3 \mathrm{ds}{ }^{\circledR}$ ha sido utilizado en la literatura para la captura de las imágenes perspectivas $\boldsymbol{C}_{\boldsymbol{k}, \boldsymbol{l}}(\boldsymbol{i}, \boldsymbol{j})$ utilizando una cámara virtual bajo la configuración de cámara simple [7]. Por otro lado, diferentes empresas e investigadores utilizan librerías libres de OpenGL para el desarrollo de sus propias aplicaciones [24, 29, 34]. Otro de los softwares que ha sido aplicado y que presenta grandes ventajas para el desarrollo de aplicaciones dirigidas a las holoimpresoras es Blender ${ }^{\mathrm{TM}}[22,29]$. Este es un software bajo licencia libre y desarrollado en Python que posibilita la creación de aplicaciones y la configuración de cámaras virtuales bajo los principios del modelo de un EH descrito en la sección 2. Blender fue utilizado en este trabajo para crear y editar las escenas 3D y 
por último para crear y configurar las cámaras virtuales con el objetivo de aplicar el método de cámara truncada.

El método de cámara truncada es un caso que se deriva del método de apertura [15, 24, 34]. Este utiliza una cámara virtual que se desplaza por cada una de las posiciones correspondientes de los hogels. Para implementar el método de cámara truncada se requiere configurar la escena en el software de computación gráfica como se ilustra en la Fig. 6. Se crea inicialmente un plano cámara C igual en tamaño al EH-PC que será registrado, en la Fig. 6 el plano del EH-PC se denota por la letra H. El plano cámara es dividido en partes iguales por la cantidad de hogels $N \times M$ que serán registrados en el EH-PC. Cada una de estas posiciones corresponden a las posiciones en que deben ser capturadas el conjunto de imágenes $\boldsymbol{C}_{\boldsymbol{i}, \boldsymbol{j}}$. La separación entre cada una de las posiciones de la cámara es igual al tamaño del hogel. Adicionalmente, como la cantidad de rayos emitidos por cada hogel depende de la resolución $K x L$ pixeles del SLM y del FOV $\theta$ del objetivo de escritura, la resolución de cada imagen $\boldsymbol{C}_{i, j}$ se ajusta a la resolución del SLM y el FOV de la cámara $\theta_{\text {cam }}$ se iguala al FOV $\theta$. De esta forma, la configuración del método de cámara truncada queda definida por las restricciones de la ecuación (5). Finalmente, cada imagen hogel es obtenida a partir de la igualdad de la ecuación (2).

$$
\begin{gathered}
\text { Capturas horizontales }=N \\
\text { Capturas verticales }=M \\
\text { Resol. horizontal Cam. }=K \\
\text { Resol. vertical Cam. }=\mathrm{L} \\
\theta_{\text {cam }}=\theta
\end{gathered}
$$

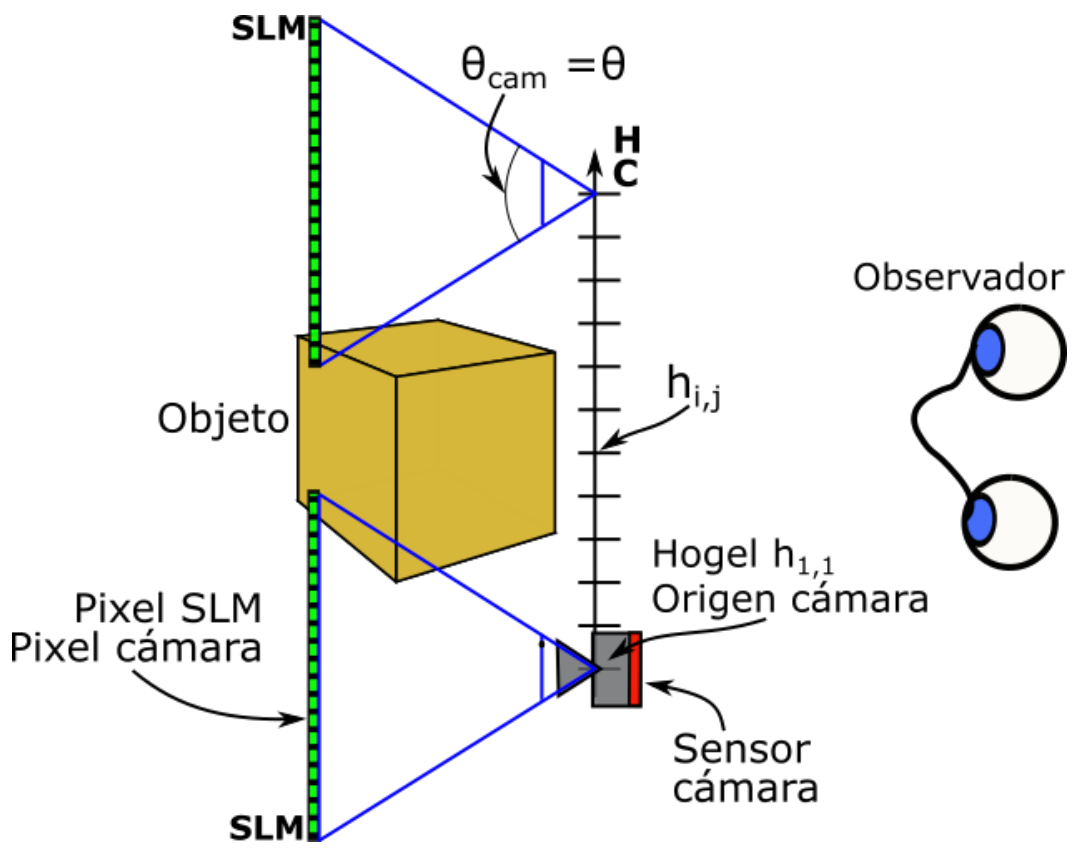

FIG. 6. Configuración geométrica del método de cámara truncada. La cámara virtual es posicionada sobre cada hogel $h_{i, j}$ del plano holograma H, su FOV $\theta_{\text {cam }}$ se ajusta para coincidir con el FOV $\theta$ del objetivo óptico de escritura y la resolución de la imagen de la cámara con la resolución del SLM empleado en la holoimpresora.

\section{3.b. Implementación Opto-mecánica}

En la Fig. 7 se ilustra un esquema de la holoimpresora desarrollada e implementada en este trabajo. En nuestro sistema es utilizado un láser HeNe de $30 \mathrm{~mW}$ como fuente de luz coherente. El haz del láser es desviado por un espejo (M1) para ser dirigido hacia el divisor de haz del sistema. Este último está compuesto por una placa $\lambda / 2$ (WP1) a la entrada de un cubo divisor de haz polarizado (CBS) para controlar la relación de intensidades entre el haz referencia y el haz objeto. Una placa $\lambda / 2$ (WP2) adicional es utilizada para compensar el estado de polarización entre los dos haces. El haz que es transmitido por el cubo divisor de haz es utilizado como haz referencia. El haz referencia está compuesto por un expansor de haz (T2) para 
iluminar la apertura Ar y definir la geometría y el tamaño del área de exposición deseado. El sistema formador de imagen L5 forma una imagen real y disminuida de la apertura Ar sobre el material fotosensible (H). Por otro lado, el haz reflejado por el CBS es utilizado como haz objeto. La polarización de este haz es ajustado por la placa $\lambda / 2$ WP2 y posteriormente es expandido por el sistema de lentes T1. El haz objeto incide sobre la apertura Ao, la cual determina la geometría y el tamaño del área de exposición sobre el material de registro. Con los sistemas ópticos compuestos por las lentes L1-L2 y L3-L4 se forma la imagen real disminuida de la apertura Ao sobre el material fotosensible, la cual coincide en geometría y tamaño con la generada por el haz referencia. El factor de magnificación del sistema compuesto por las lentes L1-L2 y L3-L4 está definido por la ecuación (6).

$$
M_{T}=f_{2} f_{4} / f_{1} f_{3}
$$

De manera simultánea, el sistema de lentes L1-L4 es utilizado para enfocar la imagen proyectada en el SLM sobre el material fotosensible $(\mathrm{H})$. Es sobre el plano $(\mathrm{H})$ que se genera la imagen de la apertura Ao y la transformada de Fourier de la imagen presentada en el SLM. Como SLM hemos implementado una pantalla de cristal líquido (LCD) de tipo twisted nematic de resolución 1920 x 1080 pixeles con un área efectiva de registro de 1080 x 1080 pixeles. La lente L4 funciona como un sistema óptico de escritura de apertura numérica grande, que además de formar imagen de la apertura Ao sobre el plano $\mathrm{H}$, genera una imagen magnificada del LCD en un plano posterior a este. Es esta imagen la que presenta la distribución angular de intensidades de la escena. Una mayor cantidad de información de una escena puede ser generada en la medida que la apertura numérica de estos sistemas sea mayor. De esta forma, hemos diseñado nuestro propio sistema óptico de escritura L4 usando lentes comerciales. Este sistema compuesto por 7 lentes fue diseñado y optimizado en el software Zemax. Con la lente L4 desarrollada se alcanza un FOV de $60^{\circ}$ y un tamaño de hogel de $1 \mathrm{~mm}$ x $1 \mathrm{~mm}$. Finalmente, el haz objeto y el haz referencia son alineados cuidadosamente para superponerse sobre la misma área del material fotosensible. A partir del desplazador XY y del obturador mecánico (O) se expone el material de registro por cada imagen hogel.

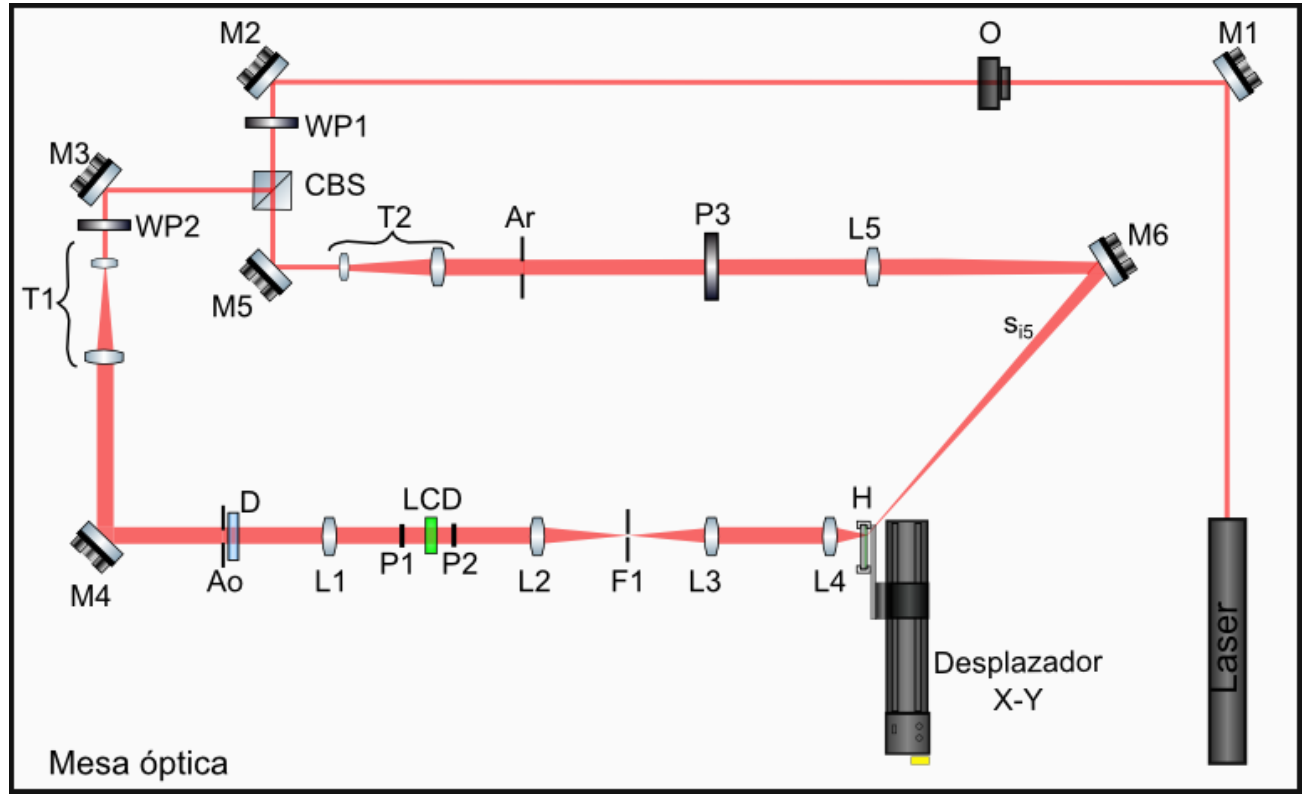

Fig 7. Esquema general de la configuración óptica de la holoimpresora implementado. un láser HeNe de $30 \mathrm{~mW}$ es utilizado como fuente de luz coherente para ser dividido en el haz objeto y el haz referencia.

\section{3.c. Implementación de control y registro}

Para controlar los diferentes elementos opto-mecánicos de la holoimpresora como lo son el obturador, el desplazador XY y el LCD, se desarrolló una aplicación en LabView que permite manipular cada uno de estos elementos para registrar de manera automática, estable y repetitiva cada uno de los hogels que componen el EH-PC. Esta aplicación permite definir los parámetros de registro como tiempos de exposición, tiempos de estabilización entre el registro de cada hogel y la proyección secuencial de cada una de las imágenes hogel. Bajo la integración entre estos sistemas, fue propuesta una metodología para el registro de los EHPC como se muestra a continuación: 
1. La escena 3D es configurada con respecto al plano del EH. Las características del objeto y las fuentes de iluminación son ajustadas en el software de computación gráfica Blender.

2. El método de cámara truncada es ajustado con los parámetros de registro definidos en la sección 3.a.

3. Las imágenes hogel son generadas y almacenadas en memoria.

4. Por cada imagen hogel es definido el tiempo de exposición.

5. Con las imágenes hogel y la lista de tiempos de exposición generadas, estas son cargadas en la aplicación de LabView para la preparación del registro.

6. Registro del EH-PC: al iniciar el primer hogel, el sistema desplaza el material de registro, espera un segundo y registra el siguiente hogel. Este proceso se realiza de manera consecutiva hasta que la última imagen hogel es registrada.

7. Realizar proceso de revelado.

\section{Resultados experimentales y discusión}

\section{4.a. EH-PC de escenas creadas en computador}

Para evaluar el correcto funcionamiento de la holoimpresora y de los métodos computacionales implementados se registraron EH-PC de $10 \mathrm{~cm}$ x $10 \mathrm{~cm}$ con una resolución de 100 x 100 hogels. Bajo estas características, el área de exposición del hogel sobre el material fotosensible es de $1 \mathrm{~mm}$ x $1 \mathrm{~mm}$. De esta forma, el desplazador XY fue configurado para desplazarse por cada hogel un tamaño de paso de $1 \mathrm{~mm}$ en ambas direcciones. Como material de registro fue utilizado el material a base de haluros de plata Slavich PFG-01.

Para este primer experimento, el objeto que se ilustra en la Fig. 8 fue modelado en el software de computación gráfica 3D Blender. Este objeto se compone por tres sólidos rectangulares separados de manera equidistantes. Sobre el último sólido fue ubicada una flecha que apunta hacia la parte superior como sistema de referencia para la reconstrucción del EH-PC final. Utilizando el método de cámara truncada, descrito en la sección 3.a, fueron generadas las 10.000 imágenes hogel que contienen la información de paralaje del objeto. En la Fig. 9 se muestra una selección del conjunto de imágenes hogel. Para su generación, la cámara fue ubicada en el espacio correspondiente a cada uno de los hogel del EH-PC, el FOV de la cámara se ajustó para coincidir con los $60^{\circ}$ del FOV del sistema óptico de escritura y una resolución de 1080 x 1080 pixeles fue elegida para cada imágen hogel. Para la adquisición de las imágenes se utilizó un computador con procesador Intel core i7 de 64 bits y tarjeta gráfica NVIDIA GeForce 740M. Su adquisición tomó un tiempo de 15 minutos.

Los parámetros de registro como tiempos de exposición y las imágenes hogel fueron procesados en la aplicación de control desarrollada en LabView. El registro de las 10.000 imágenes hogel tuvo una duración de 10 horas. En la Fig. 10 se muestran diferentes fotografías de la reconstrucción del EH-PC obtenido. El EHPC presenta imágenes 3D con información de profundidad y cambios de perspectivas del modelo 3D. A partir de la información de paralaje generada por el arreglo de hogels, múltiples observadores experimentan visión estereoscópica y de cambios de paralaje tanto vertical como horizontal. Las imágenes 3D se presentan dentro de un FOV de $60^{\circ}$, siendo este valor igual al FOV del objetivo de escritura diseñado. Debido al método computacional implementado, sección 3.a, las imágenes 3D no presentan ninguna distorsión geométrica del objeto y los detalles de alta resolución pueden resolverse en la etapa de reconstrucción. La buena eficiencia de difracción del EH-PC permite una fácil y correcta interpretación de la información exhibida. 
ÓPTICA PURA Y APLICADA

www.sedoptica.es

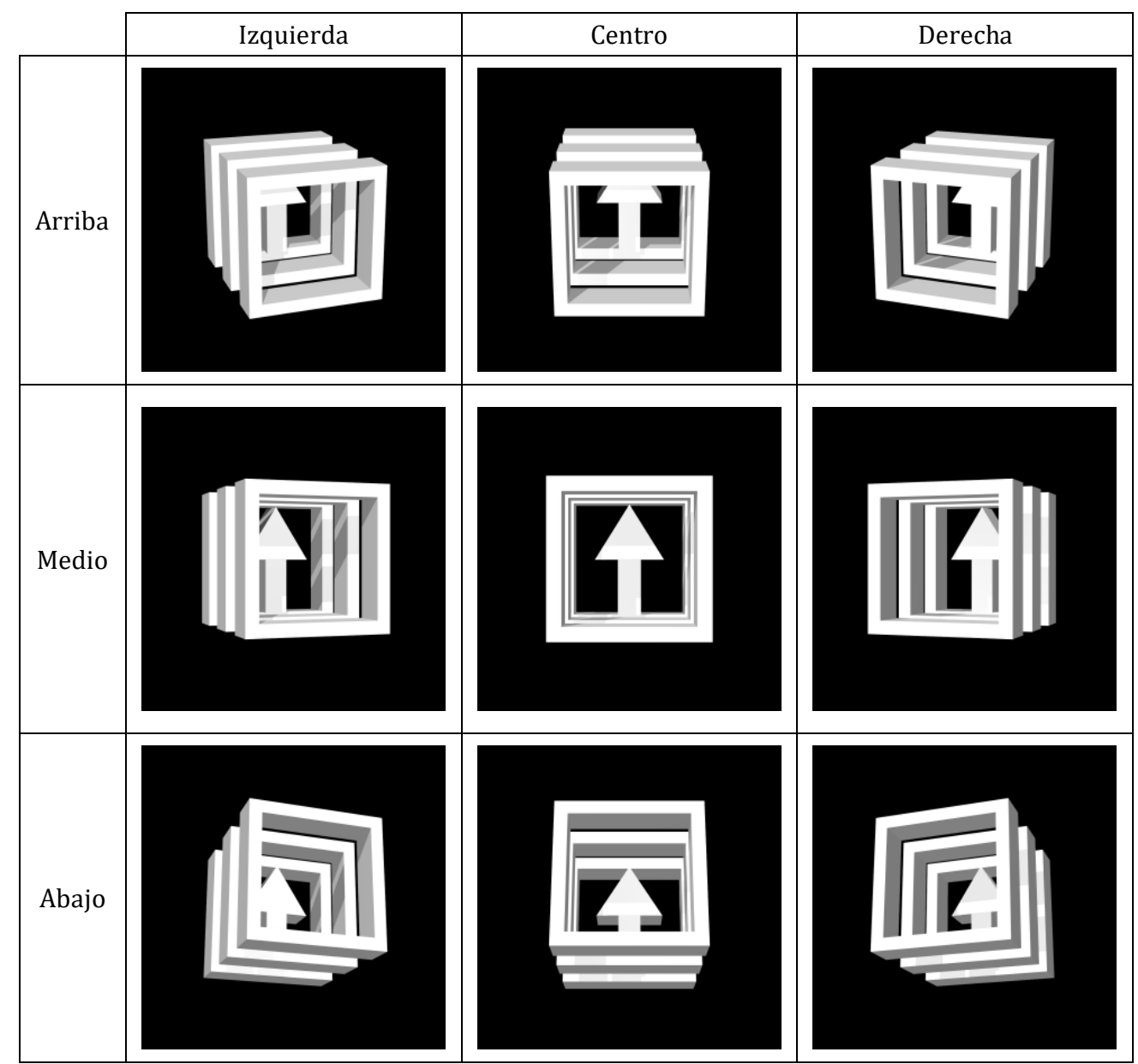

Fig. 8. Modelo 3D generado en computador usado para la síntesis del EH-PC. Se muestran 9 diferentes perspectivas del mismo objeto capturadas por una cámara virtual.

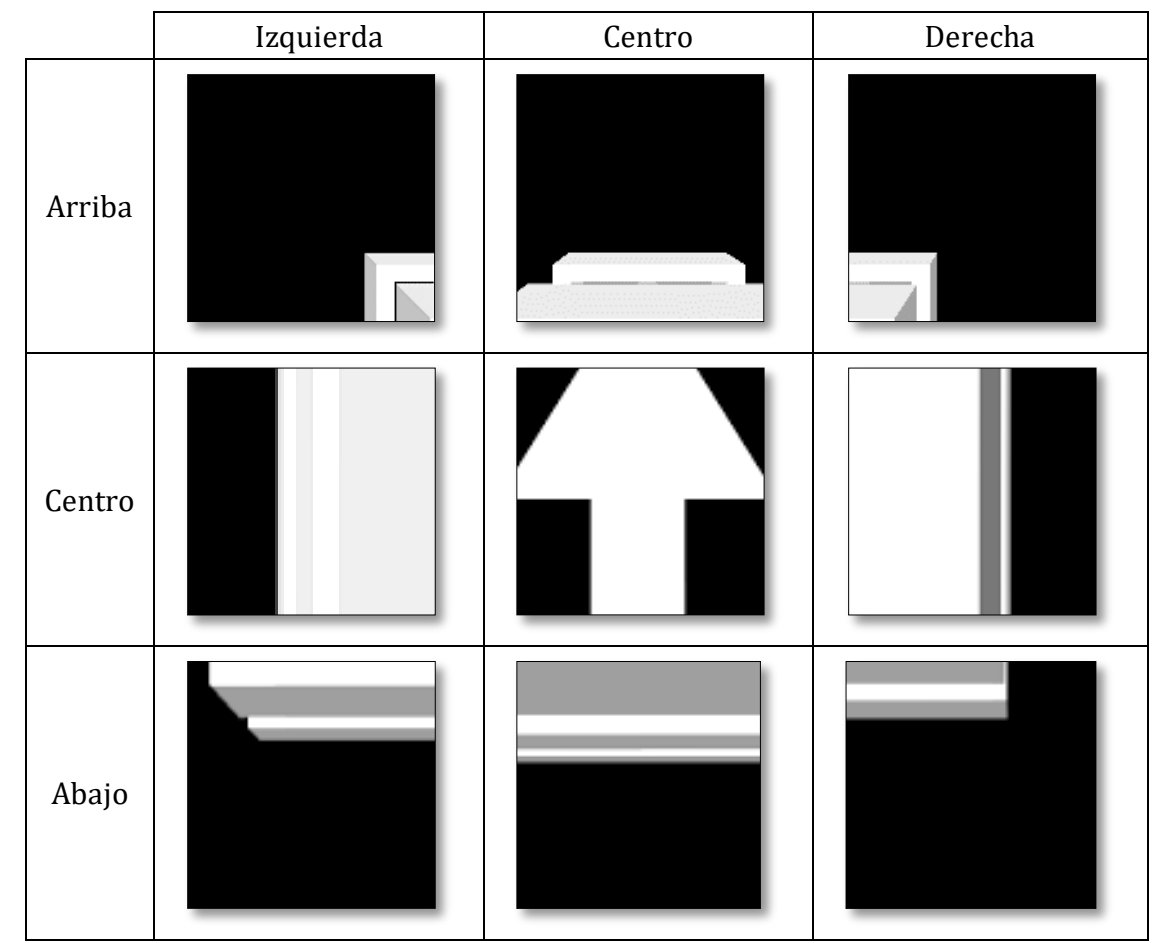

Fig. 9. Imágenes hogel generadas para el objeto 3D diseñado. La relación espacial presentada en la tabla se define con respecto a la posición en que son registradas 9 de las 10.000 imágenes hogel que conforman el EH-PC. 


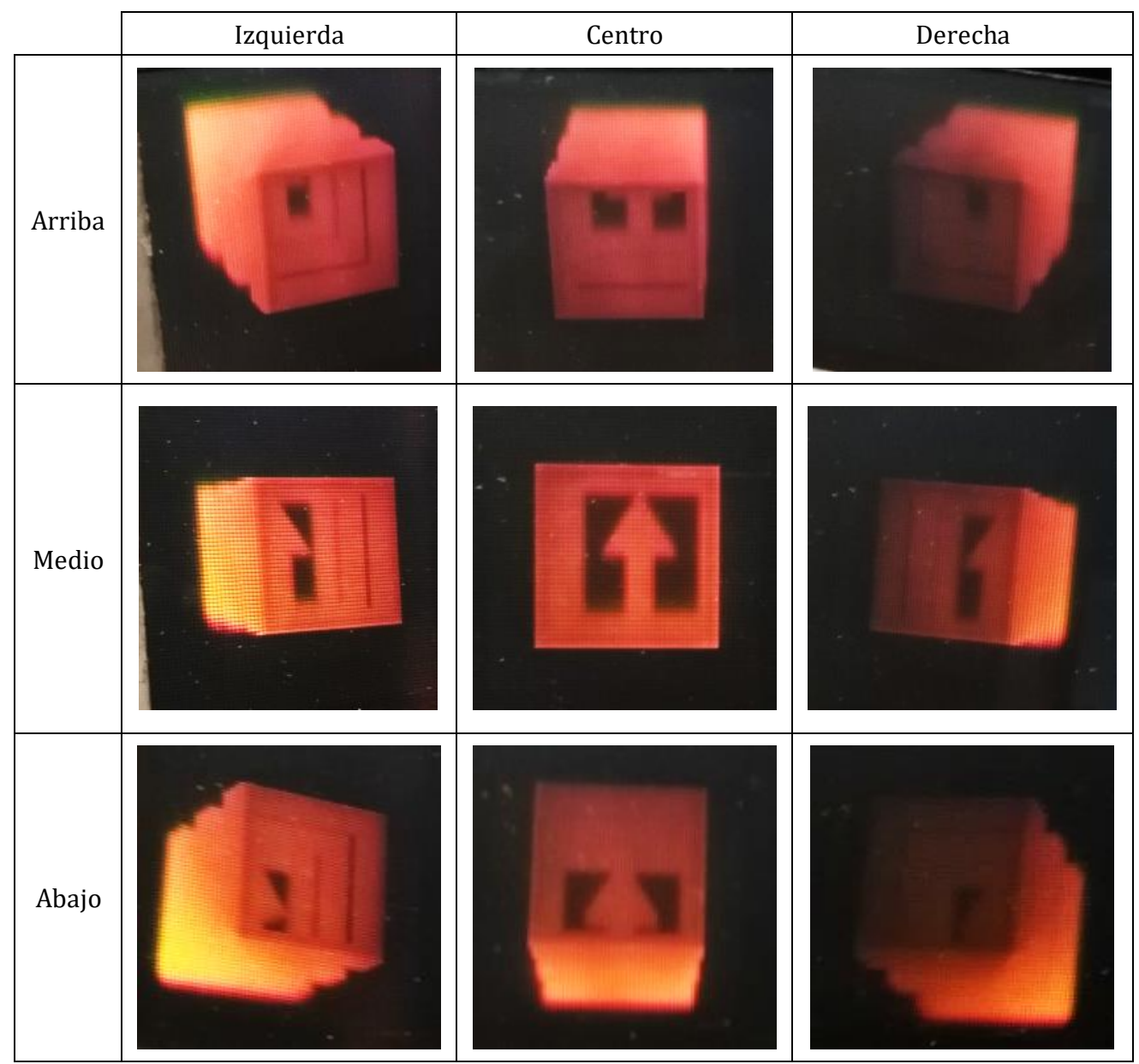

Fig. 10. Reconstrucciones del EH-PC obtenidas para diferentes posiciones de una cámara fotográfica.

\section{4.b. EH-PC de escenas reales}

Con el uso de las tecnologías computacionales, las escenas físicas pueden ser digitalizadas para ser posteriormente sintetizadas en un EH-PC. Para validar el uso de la holoimpresora en el registro de EH-PC de diferentes tipos de escena, una persona fue utilizada para crear el modelo 3D virtual y registrar su EHPC. Los modelos 3D de escenas físicas se pueden obtener a partir de una serie de fotografías con información de las diferentes perspectivas de la escena, obtenidas con una cámara fotográfica convencional. Estas son utilizadas como información de entrada en el software Recap Photo [39] en el que la información de profundidad y texturas de la escena es extraída para componer una nube de puntos 3D asociada a las características físicas de la escena [7,37]. Posteriormente, el modelo 3D es editado y escalado a las dimensiones reales del EH-PC para obtener las imágenes hogel mediante el método de cámara truncada. Una imagen del modelo 3D obtenido se muestra en la Fig. 11. De igual forma que el experimento realizado en la sección 4.a, un EH-PC de 100 x 100 hogel con un tamaño de hogel $1 \mathrm{~mm} \times 1 \mathrm{~mm}$ fue registrado para el objeto de la Fig. 11. La información que compuso cada una de las imágenes hogel fue obtenida mediante el método de cámara truncada con $N=M=100, K=L=1080$ y $\theta_{\text {cam }}=60^{\circ}$. Una selección de 9 imágenes de las 10.000 imágenes hogel obtenidas se muestran en la Fig. 12. 


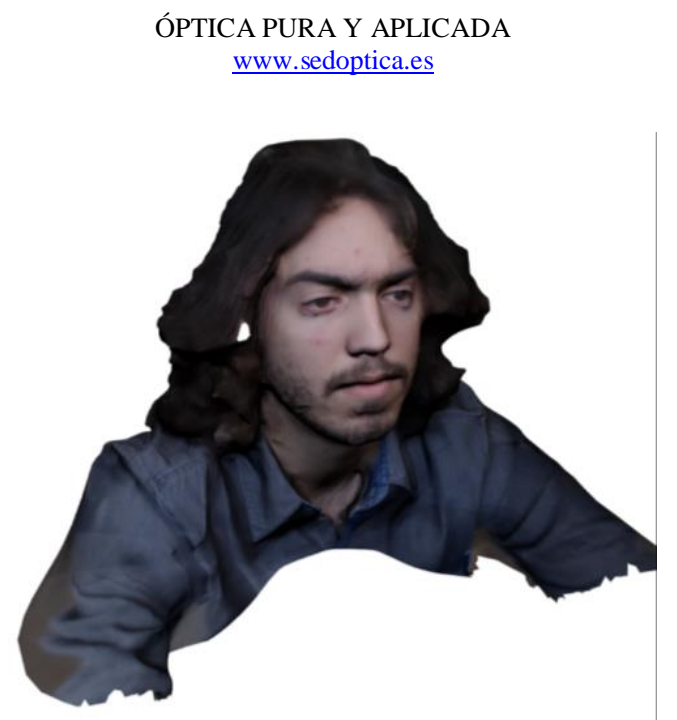

Fig. 11. Modelo 3D generado a partir de una persona. El modelo 3D es editado y ajustado a las condiciones de registro del EH-PC usando el software de computación gráfica 3D Blender.

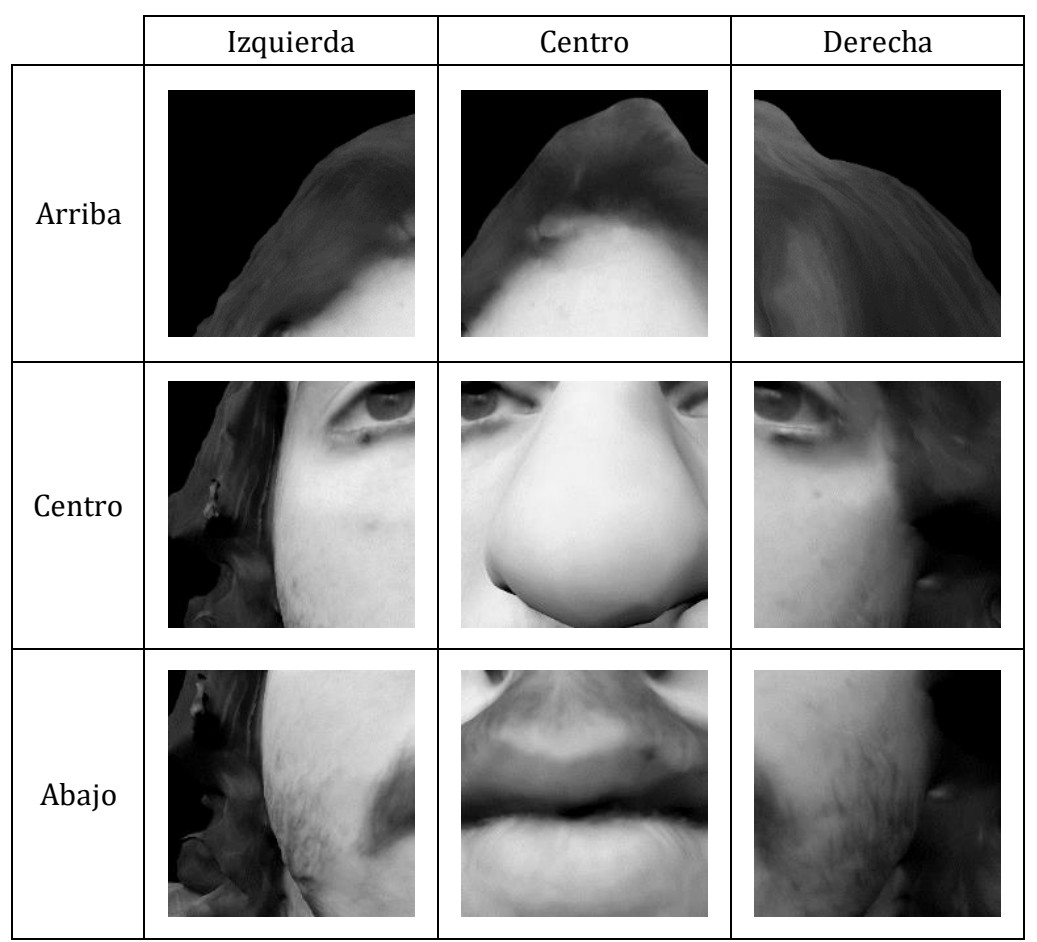

Fig. 12. Imágenes hogel generadas para el objeto 3D reconstruido en computador. La relación espacial presentada en la tabla se define con respecto a la posición en que son registradas 9 de las 10.000 imágenes hogel que conforman el EH-PC.

En la Fig. 13 se ilustran 9 fotografías de la reconstrucción del EH-PC obtenido para diferentes posiciones de la cámara. En este se puede apreciar una imagen 3D con gran nivel de realismo de la escena elegida. Su calidad deriva en la alta resolución con la que son generadas las imágenes y su ajuste con las condiciones geométricas del EH-PC. Un observador que se encuentre enfrente de este EH podrá experimentar una percepción estereoscópica y de paralaje tanto horizontal como vertical. Adicionalmente, detalles como por ejemplo las diferentes texturas del rostro y de los hombros pueden ser apreciados fácilmente. 


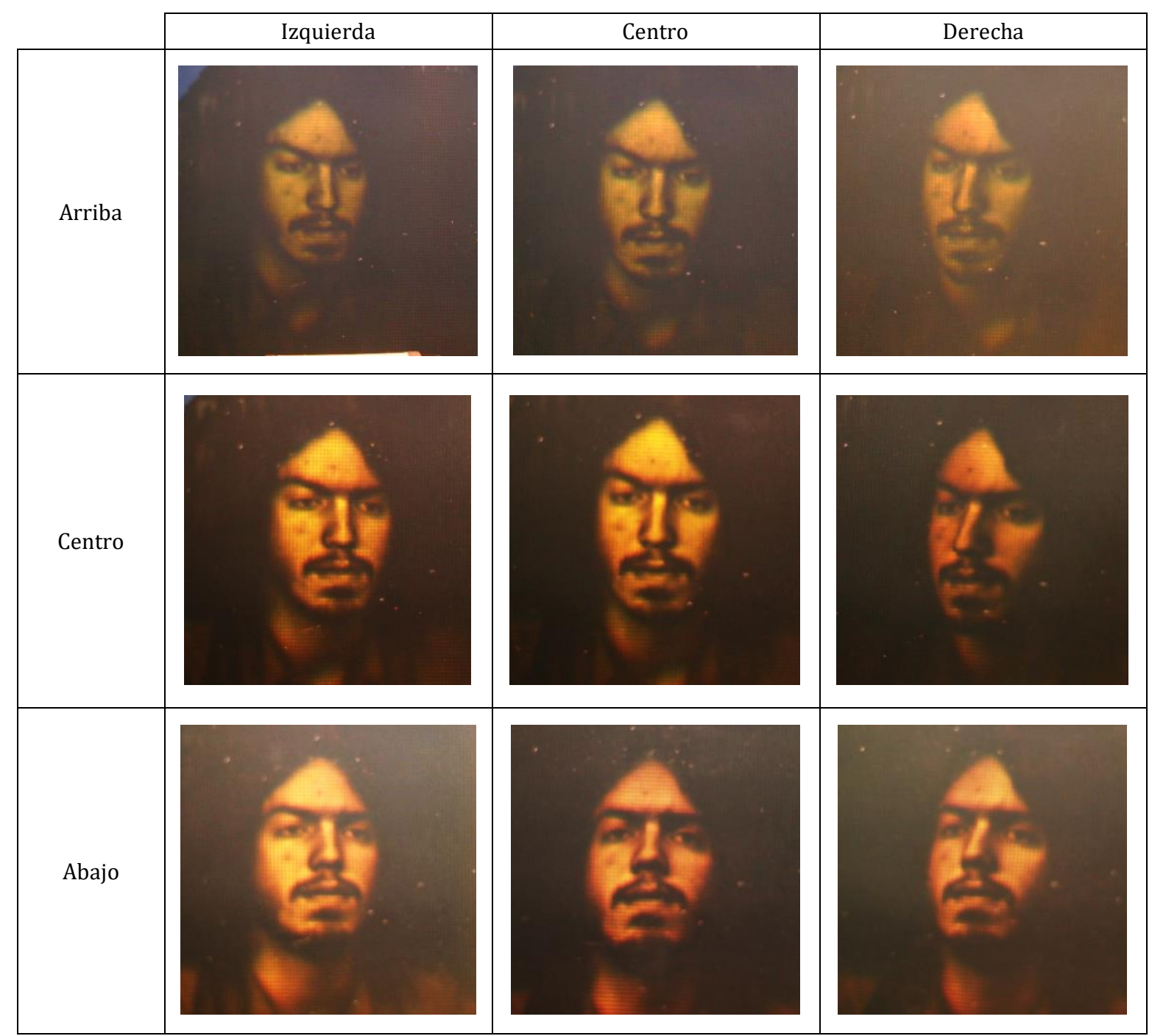

Fig. 13. Reconstrucciones del EH-PC de una persona obtenidas para diferentes posiciones de una cámara fotográfica.

\section{Conclusiones}

Con el desarrollo de este trabajo se ha logrado diseñar e implementar una holoimpresora que permite obtener hologramas sintéticos de paralaje completo de escenas físicas y modelos 3D creados en computador. Para esto, se diseñó y evaluó un sistema óptico para el registro de cada uno de los hogels que componen el EH-PC. Con el sistema implementado se obtuvieron EH-PC con FOV de $60^{\circ}$ y con tamaños de hogel de $1 \mathrm{~mm}$ x $1 \mathrm{~mm}$. Para la implementación computacional, se desarrolló un método que permite obtener las imágenes hogel de manera directa para el registro de los EH-PC. La información generada por el método computacional implementado satisface las condiciones geométricas del sistema de registro y por tanto, la manera en que la información tridimensional es exhibida por el EH-PC.

Como resultado de este desarrollo, los EH-PC obtenidos producen imágenes 3D virtuales de objetos 3D creados en computador y de objetos que hacen parte del mundo físico. Los EH-PC obtenidos generan en los observadores una experiencia estereoscópica y de paralaje completo, permitiéndoles percibir plenamente la tridimensionalidad y los cambios de perspectiva de las escenas 3D. Para mejorar la experiencia visual, pueden ser implementados sistemas ópticos que alcancen FOV mayores y disminuyan el tamaño del hogel, produciendo EH-PC de mayor resolución.

\section{Agradecimientos}

Los autores agradecen el apoyo de la Dirección de Investigación de la Universidad EAFIT. Este trabajo fue financiado por presupuesto de investigación de la Universidad EAFIT, proyecto interno "Mejoramiento de la calidad de las imágenes holográficas registradas por escritura directa” (Código 767-000082). 